\title{
O sentido do trabalho para mulheres após a licença maternidade: um estudo com profissionais de educação
}

\section{The meaning of work for women after maternity leave: a study with education professionals}

\author{
Cristiano de Jesus Andrade', Lucieneida Dováo Praun², \\ Hilda Rosa Capelão Avoglia ${ }^{3}$
}

\section{Resumo}

\begin{abstract}
Não raramente, o fim do período de licença maternidade tende a desencadear nas mulheres diversos tipos de sofrimento psíquico. Este, por sua vez, resulta de fatores diferenciados presentes na vida de cada trabalhadora. Este artigo apresenta resultados parciais de um estudo que teve por objetivo analisar o sentido do trabalho para mulheres egressas da licença maternidade. Adotou-se como método de investigação o estudo de caso. Participaram da pesquisa 13 servidoras da área da educação, todas vinculadas a administração pública de um município do Estado de Minas Gerais. A entrevista, qualitativa, semiestruturada, foi utilizada como instrumento de coleta, cujos resultados foram analisados à luz das premissas teóricas da psicodinâmica do trabalho. Os resultados indicaram que além de ensinar e aprender, em seus discursos trazem a afetividade como fator fundamental para o sentido no trabalho junto a crianças, mas também reconhecem que a busca por profissionalização é de extrema relevância para o desenvolvimento das atividades perante ao público.
\end{abstract}

Palavras-chave: Sentido no trabalho. Servidoras públicas. Licença maternidade. Psicodinâmica do trabalho.

\begin{abstract}
Not infrequently, the end of the period of maternity leave tends to trigger in women various types of psychic suffering. This, in turn, results from differentiated factors present in the life of each worker. This article presents partial results of a study that aimed to analyze the meaning of work for women after maternity leave. The case study was adopted as a research method. A total of 13 servants from the education area participated in the study, all of them linked to the public administration of a municipality in the state of Minas Gerais. The qualitative, semistructured interview was used as a collection tool, whose results were analyzed in light of the theoretical premises of work psychodynamics. The results indicated that in addition to teaching and learning, in their discourses they bring affectivity as a fundamental factor for the meaning in the work with children, but also recognize that the search for professionalization is of extreme relevance for the development of the activities towards the public.
\end{abstract}

Keywords: Sense at work. Public servants. Maternity leave. Psychodynamics of work.

\footnotetext{
1 Doutorando em Psicologia da Saúde pela Universidade Metodista de São Paulo (2018). Professor convidado no curso de MBA em Psicologia Organizacional e Gestão de Pessoas da UNIFENAS Campus Alfenas/MG

2 Doutora em Sociologia pela Universidade Estadual de Campinas (2014). Professora visitante na Universidade Federal do ABC (UFABC).

3 Doutora em Psicologia Escolar e do Desenvolvimento Humano pelo Instituto de Psicologia da Universidade de São Paulo (2006). Docente colaboradora do Programa de Pós-Graduação Stricto Senso em Psicologia da Saúde da Universidade Metodista de São Paulo. Docente do Programa de Pós-Graduação em Psicologia e Políticas Públicas da Universidade Católica de Santos.
} 


\section{Introdução}

$\mathrm{Na}$ trajetória dos estudos sobre maternidade, autores como Rocha, Mota e Matos (2011); Pintanel, Gomes e Xavier (2013); Oliveira e Poletto (2015) e Roncallo, Miguel e Freijo (2015), vem dando uma ênfase a temática referente ao vínculo mãe-bebê, porém poucas são as referências que se encontram refletindo sobre o dilema vivenciado pela mulher frente à necessidade de trabalhar e o desejo de se dedicar integralmente aos cuidados maternos. Dados estes que podem vir a gerar perdas na relação mãebebê, haja vista que o bem-estar da mulher também é condição fundante para que se possa estabelecer saúde mental e desenvolvimento favorável ao bebê.

Sendo assim, este estudo parte do pressuposto de que investigações sobre o sentido que as mulheres atribuem ao fato de terem que trabalhar, bem como ao seu estado emocional quanto mãe frente a separação do bebê para o retorno ao seu posto de trabalho também são necessárias, não apenas para orientar as medidas preventivas quanto o vínculo mãe-bebê, mas também para que tais pesquisas tenham a possibilidade de lançar alguma luz sobre problemas básicos que poderão vir a ser desencadeados no desenvolvimento da relação mãebebê e para a realização das atividades de trabalho da mulher como um todo. Isso porque se sabe que só se consegue aliviar alguns sofrimentos no trabalho, quanto se identifica o sentido que este atribui ao sujeito trabalhador, aos seus pares, bem como para a organização como um todo.

Buscando contemplar algumas contribuições a respeito da temática, inicialmente será realizada uma breve reflexão a cerca das mulheres mediante a gestação e os principais sentimentos experimentados por estas no período puerperal, para posteriormente apresentar como fundamentação teórica estudos que discutem maternidade $\mathrm{X}$ trabalho, assim como os pensamentos de Dejours, além de autores que possam vir a dialogar com as idéias trazidas por este.

Segundo Pavoni (2015), ao longo do período gestacional é natural que a mãe venha a imaginar seu bebê. Isto possibilita que esta ofereça um lugar para ele ocupar em sua existência, tornando-se essencial essa construção imaginativa materna, tanto para a criança que está por nascer quanto para a mãe que se nota como alguém que colocará um ser no mundo. Sendo assim, a importância dessa imaginação se dá no sentido de que a partir disto o bebê se tornará objeto privilegiado da mãe, onde esta passará a investir libidinalmente neste. O que é fundamental para a relação mãe-bebê.

Pereira et al. (2014), acreditam que desde o período gestacional, mãe e filho constroem uma interação. Esta por sua vez, estrutura-se em diversas formas, manifestando possibilidades de relações de dependência/autonomia, afeto/desafeto, onipotência e impotência frente a fragilidade e força da vida.

Complementando este pensamento, Silva (2016), aponta que as primeiras relações materno-infantis vão se constituir desde o nascimento do bebê até os primeiros anos de vida. É uma relação na qual o par mãe-bebê se comunicará pela relação recíproca que foi desenvolvida desde a concepção, passando pelo seu desenvolvimento em útero, até o instante do nascimento.

Rodrigues e Bolsoni (2011) descreveram as fases do estresse das mães em dois momentos, sendo acentuado, no terceiro trimestre de gestação e no pós-parto. No que tange ao pós-parto, tornase relevante salientar que é exatamente no contato inicial com o bebê, mais precisamente de 0 até 3 meses quando se elabora o puerpério, a mãe experimenta os mais diversos tipos de conflitos, como os sentimentos provocados pelas reflexões que a levam a contatar seu retorno ao trabalho.

\section{Maternidade e Trabalho}

Lopes et al. (2005) pesquisaram sentimentos das mães primíparas diante da situação de separação de seus bebês e também os sentimentos em relação aos cuidadores alternativos. Verificaram por intermédio da referida pesquisa que $66 \%$ das 47 
mães entrevistadas relataram sentimentos negativos no momento da separação de seus bebês, tais como preocupação, apreensão, medo, tristeza e ansiedade.

Com base nos achados de Piccinini et al. (2008), pode-se identificar que, de fato, a chegada de um filho interfere tanto positiva como negativamente na vida da mulher, e as atividades profissionais tendem a ficar em segundo plano.

No entanto, Dejours (2005) nos mostra que um aspecto relevante na procura do prazer e defesa diante do sofrimento no trabalho é a mobilização subjetiva, ou seja, o processo pelo qual o sujeito se engaja e consegue fazer uso da subjetividade, inteligência prática e do coletivo para transformar os fatores da organização do trabalho causadores de sofrimento em prazer. Dessa forma, conforme Dejours (1999), o trabalho transita em um território ambivalente, em outras palavras, tanto pode dar origem a processos de alienação e mesmo de descompensação psíquica, como pode ser fonte de saúde e instrumento de emancipação.

Pensando no trabalho feminino, um problema recorrente, conforme aponta Lima (2012), diz respeito à falta de reconhecimento das atividades das trabalhadoras, especialmente no trabalho de cuidado, ou atividades domésticas, desconsiderandose, muitas vezes, que as atividades relacionadas ao cuidado com o outro implicam efetivamente em trabalho (MOLINIER, 2008).

Ainda segundo Lima (2012), a naturalização do ato de cuidar impede que o cuidar seja percebido e reconhecido como trabalho. Impede que se observe que é nesta experiência do trabalhar que a forma de cuidar se aperfeiçoa, não simplesmente pela boa vontade, mas por condições organizacionais favoráveis.

Em outras palavras, observando a relação que se desdobra do conflito entre maternidade e inserção no mercado de trabalho apropriando-se da perspectiva dejouriana, o que hoje ambivalentemente é compreendido como perda, representada pelo sofrimento em detrimento da separação do bebê, pode ser ressignificado como ganho, a depender dos suportes oferecidos à mãe trabalhadora dentro e fora do trabalho.

No entanto, para Dejours, Abdoucheli e Jayet (1994) as pressões resultantes da organização do trabalho podem desestabilizar a saúde mental. Dejours (1994) inclusive afirma que o trabalho passa de sofrimento a prazer quando a qualidade do trabalho é reconhecida e os desânimos e contradições adquirem sentido. Nesse contexto, todo esse sofrimento não somente prestou uma contribuição a organização do trabalho, mas também, em compensação, fez do sujeito um ser diferente daquele que ele era antes do reconhecimento de sua contribuição.

Segundo Dejours (2007), quando a atividade do trabalhador é reconhecida e valorizada pela organização, ou pelos demais, o trabalho se torna estruturante na identidade do indivíduo, mas quando esta mesma atividade não é significativa para o sujeito, para a organização nem para a sociedade, ela pode ser fonte de uma forma particular de sofrimento. Assim, pode-se dizer que o mesmo trabalho que pode servir de fonte de construção de identidade para o sujeito que trabalha, contribuindo para sua saúde mental, pode também adoecer.

Neste sentido, Ribeiro e Leda (2004, p. 79), acreditam que:

"O trabalho, bem como os demais papeis exercidos pelas mulheres deveriam ser reconhecidos como fonte de realização e de construção de identidade, porém vem sendo contrariamente percebido como gerador de sofrimento e, em casos mais graves, até de adoecimento".

Conforme afirma Oliveira (2003, p. 7):

[...] o trabalho, quando perpassa a via do reconhecimento, contribui para a construção da identidade dos sujeitos, identidade esta responsável pela proteção da saúde mental. O sofrimento capaz de gerar adoecimento seria a 
inexistência de possibilidades, a limitação do ser humano a um estado de paralisia. Um risco que inviabiliza a construção da identidade e integridade dos sujeitos. (OLIVEIRA, 2003, p. 7).

No que diz respeito especificamente a inserção das mulheres no mercado de trabalho, pesquisas vêm buscando compreender o impacto da maternidade na permanência da mulher neste espaço (PAZELLO, 2006; SOUZA; RIOS-NETO; QUEIROZ, 2011). No entanto, esses estudos não buscam encontrar causalidades, mas associação entre esses dois fenômenos, eliminando o que Souza, Rios-Neto e Queiroz (2011) chamam de causas endógenas.

Heilman e Okimoto (2008) também investigaram os efeitos da maternidade no mercado de trabalho. Os autores buscaram analisar a maternidade e o retorno da mulher trabalhadora a suas atividades profissionais. Os resultados apontaram que a maternidade tem impacto negativo, considerando que o status materno pode impedir o progresso na vida profissional, devido às angústias de ter que conciliar vida pessoal/mãe com sua reinserção no trabalho.

Autores como Martins, Abreu e Figueiredo (2014); Pinquart e Teubert (2010) concordam que são geralmente as mulheres quem mais desinvestem profissionalmente para gerir os múltiplos papeis após a chegada do bebê. É consensual entre estes autores que, em caso de incompatibilidade ou dificuldades na conciliação do papel profissional com o familiar, a abdicação da vida profissional naturalmente acontece por parte destas.

\section{Trabalho Feminino e a Saúde Mental}

Neste sentido, torna-se relevante pensar na relação destas vivências experimentadas pela mulher trabalhadora com a promoção de sua saúde mental. Uma vez que mediante a necessidade de trabalhar e da angústia de deixar o filho sobre os cuidados de outras pessoas, a mulher tende a desenvolver modos de defesa para tal enfrentamento e isso só será possível, entre outros recursos a que tenha acesso, por meio da mobilização de sua resistência ao fracasso e de inteligência subjetiva, já que não se trata de uma questão apenas individual. Assim, o trabalho, conforme Dejours (1987), é atividade central na vida humana e, como tal, para que se constitua como potencializador da saúde, precisa fazer sentido para o sujeito que o desenvolve, para seus pares e para a sociedade. Isso nos leva a compreender que, o sentido do trabalho é formado por dois componentes seu conteúdo significativo tanto em relação ao sujeito como no que diz respeito ao objeto. No que tange ao conteúdo significativo do trabalho em relação ao sujeito, o autor identifica as dificuldades práticas das tarefas, a significação da tarefa acabada em relação a uma profissão, noção que contém ao mesmo tempo a ideia de evolução pessoal, de aperfeiçoamento, e a posição social implicitamente ligada ao posto de trabalho determinado.

O sentido do trabalho, desta forma, permite a construção da identidade pessoal e social de quem trabalha por meio das tarefas e atividades que executa, permitindo que consiga se identificar com aquilo que realiza. Quanto ao conteúdo significativo do trabalho em relação ao objeto, Dejours (2007, p. 40) destaca que ao mesmo tempo em que a atividade de trabalho comporta uma significação narcísica, a mesma pode suportar investimentos simbólicos e materiais destinados a um outro, isto é, ao objeto. A realização do trabalho pode também veicular uma mensagem simbólica para alguém, ou contra alguém. A atividade do trabalho, pelos gestos que implica, pelos instrumentos que movimenta, pelo material tratado, pela atmosfera na qual opera, veicula um certo número de símbolos. A natureza e o encadeamento destes símbolos dependem, ao mesmo tempo, da vida interior do sujeito, do que introduz de sentido simbólico no que o rodeia e no que faz. 
Diante do exposto, o objetivo deste artigo é apresentar resultados parciais de pesquisa sobre o sentido do trabalho na perspectiva de mulheres egressas da licença maternidade.

\section{Fundamentação Metodológica}

O estudo realizado foi de natureza qualitativadescritiva, cuja definição parte do princípio de que o conhecimento é produzido conforme o que os fenômenos da vida em geral representam para as pessoas (TURATO, 2003).

Por outro lado, a compreensão singular de eventos, sejam eles quais forem, é o princípio básico do estudo de caso, categoria em que se enquadra essa investigação. Nessa forma de pesquisa qualitativa, segundo Heloani e Lancman (2004), o objeto estudado é tratado como único, como representação particular da realidade. Assim, cada caso, destarte sua similitude com outros, é, concomitantemente, diferente, devendo ser "desvelado" e estudado com e pelas suas idiossincrasias, em uma situação ou em determinado problema.

\section{Participantes}

A escolha das participantes foi deliberada de uma amostra determinada, com características definidas (TURATO, 2003). A este modo, foram entrevistadas 13 servidoras públicas concursadas de uma prefeitura situada no sul de Minas Gerais, sendo que todas se encontram atuando junto à Secretaria Municipal de Educação, tendo sido entrevistadas: duas professoras (uma atuante no ensino fundamental e outra no ensino médio), duas supervisoras pedagógicas, duas berçaristas, duas merendeiras, uma auxiliar de serviços gerais (registro único de entrada em licença maternidade no período de 2014 e 2015), duas auxiliares de educação inclusiva, e duas auxiliares de desenvolvimento infantil.

A idade das mulheres trabalhadoras/mães participantes deste estudo varia entre 30 e 44 anos, sendo todas nascidas no Estado de Minas Gerais. Entre as entrevistadas, 10 se autodeclararam brancas, outras duas declararam-se da cor preta e uma da cor parda, todas são casadas, tendo entre um e três filhos, analisando que, entre estas, nove assinalaram serem mães de dois filhos, ao passo que três afirmam terem gerado três filhos e apenas uma é mãe de uma filha.

Quanto a religião, as trabalhadoras dividem-se entre as que se declararam católicas (7) e evangélicas (6). No tocante à escolaridade, cinco relatam ter concluído o ensino superior, quatro apontam terem ensino superior com Pós-Graduação Lato Senso, 3 possuem ensino médio completo e uma, ensino superior incompleto.

Entre a totalidade das 13 participantes, 11 afirmam que em suas casas a principal fonte de renda provém do marido. Duas das entrevistadas apontam serem elas mesmas as principais provedoras. Considerando que quatro relatam que, junto à renda do parceiro, somam de $\mathrm{R} \$ 937,01$ a $\mathrm{R} \$ 2.811,00$ ao mês, cinco relatam que a família recebe de 3 a 6 salários mínimos (de R\$ 2.811,01 a R \$ 5.622,00) e quatro recebem de 6 a 9 salários mínimos (de R\$ $5.622,01$ a $\mathrm{R} \$ 8.433,00)$. 
Quadro 1 - Descrição sociodemográfica das participantes.

\begin{tabular}{|c|c|c|c|c|c|c|c|c|}
\hline Part. & $\begin{array}{l}\text { Denominação/ } \\
\text { Profissão }\end{array}$ & Idade & Etnia & Escolaridade & Religião & $\begin{array}{c}\text { Estado } \\
\text { Civil }\end{array}$ & Filhos & $\begin{array}{l}\text { Renda } \\
\text { Familiar }\end{array}$ \\
\hline 1 & $\begin{array}{c}\text { Auxiliar de } \\
\text { desenvolvimento } \\
\text { infantil } 1\end{array}$ & 36 & Branca & $\begin{array}{l}\text { Pós-graduação } \\
\text { Lato Senso } \\
\text { completa }\end{array}$ & Evangélica & Casada & 1 & $\begin{array}{c}6 \text { a } 9 \\
\text { salários } \\
\text { mínimos }\end{array}$ \\
\hline 2 & $\begin{array}{c}\text { Auxiliar de } \\
\text { desenvolvimento } \\
\text { infantil } 2 \\
\end{array}$ & 40 & Branca & $\begin{array}{l}\text { Ensino superior } \\
\text { completo }\end{array}$ & Católica & Casada & 2 & $\begin{array}{c}6 \text { a } 9 \\
\text { salários } \\
\text { mínimos }\end{array}$ \\
\hline 3 & $\begin{array}{c}\text { Auxiliar de educação } \\
\text { inclusiva }\end{array}$ & 30 & Preta & $\begin{array}{l}\text { Ensino superior } \\
\text { completo }\end{array}$ & Evangélica & Casada & 3 & $\begin{array}{c}3 \text { a } 6 \\
\text { salários } \\
\text { mínimos }\end{array}$ \\
\hline 4 & $\begin{array}{l}\text { Auxiliar de educação } \\
\text { inclusiva }\end{array}$ & 40 & Branca & $\begin{array}{l}\text { Pós-graduação } \\
\text { Lato Senso } \\
\text { completa }\end{array}$ & Católica & Casada & 2 & $\begin{array}{c}3 \text { a } 6 \\
\text { salários } \\
\text { mínimos }\end{array}$ \\
\hline 5 & $\begin{array}{l}\text { Auxiliar de serviços } \\
\text { gerais }\end{array}$ & 34 & Preta & $\begin{array}{l}\text { Ensino médio } \\
\text { completo }\end{array}$ & Evangélica & Casada & 3 & $\begin{array}{c}1 \text { a } 3 \\
\text { salários } \\
\text { mínimos }\end{array}$ \\
\hline 6 & Berçarista 1 & 38 & Branca & $\begin{array}{l}\text { Ensino superior } \\
\text { completo }\end{array}$ & Católica & Casada & 2 & $\begin{array}{c}3 \text { a } 6 \\
\text { salários } \\
\text { mínimos }\end{array}$ \\
\hline 7 & Berçarista 2 & 39 & Branca & $\begin{array}{l}\text { Ensino superior } \\
\text { incompleto }\end{array}$ & Evangélica & Casada & 2 & $\begin{array}{c}1 \text { a } 3 \\
\text { salários } \\
\text { mínimos }\end{array}$ \\
\hline 8 & Merendeira 1 & 30 & Branca & $\begin{array}{l}\text { Ensino médio } \\
\text { completo }\end{array}$ & Evangélica & Casada & 3 & $\begin{array}{c}1 \text { a } 3 \\
\text { salários } \\
\text { mínimos }\end{array}$ \\
\hline 9 & Merendeira 2 & 34 & Branca & $\begin{array}{l}\text { Ensino médio } \\
\text { completo }\end{array}$ & Católica & Casada & 2 & $\begin{array}{c}1 \text { a } 3 \\
\text { salários } \\
\text { mínimos }\end{array}$ \\
\hline 10 & Professora 1 & 38 & Branca & $\begin{array}{l}\text { Ensino superior } \\
\text { completo }\end{array}$ & Evangélica & Casada & 2 & $\begin{array}{c}3 \text { a } 6 \\
\text { salários } \\
\text { mínimos }\end{array}$ \\
\hline 11 & Professora 2 & 36 & Branca & $\begin{array}{l}\text { Ensino superior } \\
\text { completo }\end{array}$ & Católica & Casada & 2 & $\begin{array}{c}6 \text { a } 9 \\
\text { salários } \\
\text { mínimos }\end{array}$ \\
\hline 12 & $\begin{array}{l}\text { Supervisora } \\
\text { pedagógica } 1\end{array}$ & 44 & Branca & $\begin{array}{l}\text { Pós-graduação } \\
\text { Lato Senso } \\
\text { completa }\end{array}$ & Católica & Casada & 2 & $\begin{array}{c}6 \text { a } 9 \\
\text { salários } \\
\text { mínimos }\end{array}$ \\
\hline 13 & $\begin{array}{l}\text { Supervisora } \\
\text { pedagógica } 2\end{array}$ & 42 & Branca & $\begin{array}{l}\text { Pós-graduação } \\
\text { Lato Senso } \\
\text { completa }\end{array}$ & Católica & Casada & 2 & $\begin{array}{c}1 \text { a } 3 \\
\text { salários } \\
\text { mínimos }\end{array}$ \\
\hline
\end{tabular}

Fonte: Elaborado pelos autores.

É relevante pontuar que três participantes nove dividem com mais quatro habitantes e uma disseram dividir a casa com mais quatro pessoas, com mais dois habitantes. 
Do ponto de vista da inserção e dinâmica de trabalho, as participantes possuem de 3 a 23 anos de serviço junto à prefeitura, salientando que a jornada de trabalho das mesmas varia entre 4 horas por dia (3 participantes) e 6 horas diárias (10 trabalhadoras). No tocante ao trabalho reprodutivo/atividades domésticas, todas se ocupam de tal fazer, no entanto, dez entrevistadas dividem as demandas domésticas com outros membros da família, ou com auxiliar contratada (apenas uma), porém três não fazem esta divisão, já que assumem tal responsabilidades sem apoio.

\section{Procedimentos}

As participantes foram convidadas, considerados os critérios anteriormente estabelecidos, por contato telefônico, onde detalhou-se o objetivo da pesquisa, bem como a importância das participações.

As entrevistas, com duração de 50 minutos cada, realizou-se no consultório de um dos pesquisadores, situado na região central da cidade.

A entrevista realizada em um único encontro teve caráter semidirigida, organizada a partir de um roteiro de questões a serem realizadas. Ressaltase que a entrevista semidirigida foi escolhida para a coleta de dados por permitir que os resultados obtidos se mantenham dentro do enfoque da pesquisa e fornecendo, ao mesmo tempo, liberdade para que a participante exteriorize outras respostas relacionadas com a temática principal.

As entrevistas gravadas foram transcritas e a posteriori feita uma segunda escuta para conferir a fidedignidade dos dados da transcrição. Os resultados serão apresentados em forma de discussão embasada nas premissas da Psicodinâmica do Trabalho. Serão levados em consideração todos os aspectos observados a partir das entrevistas. Para análise foram estabelecidas categorias identificadas nas leituras e releituras do conteúdo das entrevistas. As leituras e releituras foram realizadas dentro de um critério de atenção flutuante, que implica que o pesquisador se atentou às evidências dos fenômenos (TURATO, 2003).

A participação na pesquisa, por parte das entrevistadas, foi de livre escolha, precedida da assinatura do Termo de Consentimento Livre e Esclarecido (TCLE), tanto pela entrevistada como pelo pesquisador, com a garantia de sigilo sobre sua identificação, cabendo ainda salientar que o estudo foi aprovado pelo comitê de ética da Universidade Metodista de São Paulo. Também se solicitou a permissão para uso do gravador.

\section{Resultados e Discussão}

O estudo objetivou identificar $\mathbf{O}$ sentido do trabalho para mulheres após a licença maternidade: um estudo com profissionais de educação, baseado na perspectiva teórica de Dejours (1987). No caso desta pesquisa, pode-se identificar que a significação profunda do trabalho para cada uma das mulheres trabalhadoras egressas da licença-maternidade é uma significância própria, singularizada, ou seja, constituída a partir dos recursos desenvolvidos por cada uma. A este modo, refletindo sobre o sentido de conciliar trabalho e maternidade, bem como o que identificam como real sentido nas atividades que desenvolvem, as participantes apontaram compreender o trabalho na educação como um fator promotor de ensino e aprendizagem. Ensino, pois elas podem com suas atividades contribuir para a construção social da criança como um todo. Aprendizagem, pois acreditam que as atividades que exercem as "instigam" a aprender e a aprimorar os conhecimentos como profissionais de educação.

Além de ensinar e aprender, seus discursos trazem a afetividade como fator fundamental para o sentido no trabalho junto a crianças. Por outro lado, também reconhecem que a "busca por conhecimentos acadêmicos e profissional é de extrema relevância para o desenvolvimento das atividades junto ao público infantil. Haja vista que 
este é um recorte da comunidade que se encontra em desenvolvimento e para tanto necessitam não só compreensão de caráter pessoal, mas também estímulo profissional. Neste caso, o trabalho que realizam as provoca a estudar mais, conforme podese verificar nos relatos a seguir:

Me realizo muito também trabalhando, tanto que quando fui trabalhar como berçarista me encantei tanto com a educação que hoje faço pedagogia! Eu gosto muito, acho que a educação para as crianças pequenas como as que cuido faz muita diferença, para isso precisa de uma formação sim! Por que desde pequenininhos eles precisam de ter sim um lado afetivo, mas precisam ter os estímulos certos! (BERÇARISTA-1).

Comecei a trabalhar aqui como berçarista e isso foi me instigando, ai decidi fazer pedagogia para dar continuidade, aprender um pouco mais para ajudar eles. Por que no começo quando ele nasceu, pensei em trabalhar meio período só e cuidar dele e da casa o resto do tempo, mas quando comecei a trabalhar fui gostando, gostando do trabalho, do contato com as crianças, e isso foi me fazendo a desejar buscar a conhecer um pouco mais. Foi quando comecei a faculdade. (BERÇARISTA-2).

As trabalhadoras sugerem, conforme suas falas, atribuir às atividades profissionais o sentido de um convite ao aprimoramento. No entanto, não apenas no sentido da profissionalização para o trabalho especificamente que executam, mas também na formação pessoal/profissional a médio e longo prazos, já que vislumbram possibilidade de ascensão profissional no contexto onde atuam, visto que aprimorando seus saberes podem esperar futuramente a galgar novos degraus.

Sendo assim, trabalhar é atividade dotada de diferentes sentidos, implicados tanto na capacidade de incidir na formação das crianças com as quais interagem, como na transformação que essa atividade é capaz de desencadear a médio e longo prazo em cada uma. Tal achado dialoga diretamente com Dejours (2012a), que indica que o trabalho vivo consiste não apenas em produzir, mas também em transformar o existir do próprio sujeito, o que nos leva a resgatar o sentido do trabalho e seus componentes: o conteúdo significativo em relação ao sujeito e o significativo ao objeto. No que tange ao conteúdo significativo do trabalho em relação ao sujeito, conforme apresentado anteriormente, o autor identifica as dificuldades práticas das atividades, a significação da atividade acabada em relação a uma profissão, noção que contém ao mesmo tempo a ideia de evolução pessoal e de aperfeiçoamento e a posição social implicitamente ligada ao posto de trabalho determinado.

Com base nos discursos apresentados, o trabalho para as participantes além de provocar "encanto" como se percebe em seus modos de pensar, serve também como uma fonte de transformação e aprimoramento, visto que as emancipam para a vida como um todo e não apenas no contexto educacional. Todavia, além do aprendizado profissional, as participantes apontam como forma de sentido no trabalho a noção de "preenchimento e prazer" no âmbito pessoal e demonstram afeto para com o fazer e com as crianças. O que as fazem afirmarem "amar" o que desenvolvem como atividade, indicando que tal sentimento nutrido pode ser a mola propulsora para o "apego" que demonstraram dedicar às crianças.

Amo meu trabalho, também me preenche muito. Hoje em dia sei separar bem, quem é a supervisora e quem é a mãe, como sempre falo tudo isso me dá muito prazer porque aprendo muito. Então se tivesse que fazer tudo de novo eu faria, faria pedagogia de novo, prestaria concurso para supervisão de novo. Por que me preenche muito, me dá muito prazer o que faço. (SUPERVISORA PEDAGÓGICA-2).

O sentido maior é que eu tenho muito prazer em trabalhar com crianças, além do que lá a gente é merendeira, mas a gente também ensina para as crianças. Temos um projeto de orientação para elas, tipo na páscoa a gente ensinou eles a fazer brigadeiro de cenoura, foi lindo! Eles 
gostaram muito! Eles ficam muito próximos de mim e isso é bom até para meu psicológico, porque a gente acaba pegando muito amor neles. (MERENDEIRA-1).

Os discursos apresentados demonstram que as trabalhadoras/mães encontram em seus postos de trabalho um modo de "preenchimento" quanto ao que fazem como profissionais. No entanto, é interessante observar que mesmo atuando em áreas específicas, como supervisão e merenda, seus discursos se coadunam, levando a acreditar que o que as fazem bancar a dicotomia mãe $\mathrm{x}$ trabalhadora está relacionado ao fato do reconhecimento que as preenche. Entretanto, se no trabalho fora de casa estas mulheres constroem identidade e reconhecimento social, conforme indicaram as entrevistas, no campo das tarefas e atividades domésticas, ressaltase a condição de invisibilidade, tal como expressa o depoimento a seguir:

Para mim é um modo de tirar a gente do foco de só ser mãe, que para mim apesar de ser maravilhoso é cansativo, então o trabalho me ajuda a respirar e conhecer novas coisas. As vezes até já pensei que para que trabalhar fora de casa, porque é cansativo também, mas não me vejo hoje sem trabalhar com a educação. Eu falo que o serviço de casa às vezes se a gente ficar muito ligada nele a gente fica louca. Então para não me adoecer eu deixo isso para lá. Lavar uma louça pode esperar, cama pode também ficar sem arrumar se preciso for, porque se eu ficar ali o dia todo só me dedicando não irei conhecer novas coisas e sei que isso vai me deixar doente. (PROFESSORA-2).

Compreendendo a narrativa da trabalhadora anteriormente citada, Dejours (2012b, p. 24), salienta que "Trabalhar é vencer, ou seja, preencher o hiato entre o prescrito e o efetivo/real". No entanto, Dejours (2012, p. 24), complementa afirmando que o que se deve colocar em ação para vencer este hiato não pode ser previsto de antemão. $\mathrm{O}$ caminho a ser percorrido entre o prescrito e o efetivo deve ser a cada momento inventado ou descoberto pelo sujeito trabalhador.
No caso das participantes, que são mulheres trabalhadoras que dividem seu tempo entre suas atividades domésticas e aquelas desenvolvidas fora de casa, compreende-se que para superar tal dicotomia promotora de tensão/angústia pessoal, as mesmas devem imprimir algo a mais que vem delas para ir além do prescrito e assim lidarem com o real de um modo possível/funcional. Ao menos de um modo que dê sentido a existência delas, conforme se verifica a seguir:

Para mim é uma realização pessoal, embora eu preciso trabalhar também, porque só com o dinheiro do meu marido não daria para a gente viver, mas trabalho por que me realizo muito também. Não quero ser só dona de casa, ficar lá cuidando, quero ser profissional também. Busco mudar este perfil de dona de casa um pouco, porque acho que a gente não tem que só ser mulher e mãe, não temos que ser dependentes. Então é neste sentido que falo que é uma realização. $O$ trabalho não me deixa financeiramente depender de ninguém, posso fazer com meu dinheiro o que quiser, então este é o sentido para mim. (AUXILIAR DE EDUCAÇÃO INCLUSIVA-2).

"O trabalho além de uma valorização pessoal que antes já significava, hoje tem o sentido de poder exemplificar para ela (filha) o quanto é importante trabalhar. Como falei que sou prática, então quero que ela veja a independência da mulher, que é no trabalho que ela irá poder aprender ser independente". (AUXILIAR DE DESENVOLVIMENTO INFANTIL-1).

Dejours (2012b, p. 118), acredita que ao trabalhar, de modo geral os sujeitos esperam uma retribuição que reveste uma forma cardeal do reconhecimento. O preço a ser pago pelo reconhecimento e pelas três provas de julgamento que constituem o julgamento de utilidade e os dois julgamentos de beleza (conformidade com as regras da arte do ofício e originalidade de estilo nas soluções), deve-se ao fato de que com o reconhecimento são obtidas preciosas gratificações no registro da identidade: pertencimento a um coletivo ou a uma comunidade, de um lado, identidade singular, de outro. Assim, 
a participação ativa no coletivo e nas cooperações horizontais e verticais contém embutida uma promessa: a de poder servir-se da experiência do trabalho como mediação para construir a sua identidade, ou seja, para ampliar a robustez psíquica vis-à-vis as doenças mentais, e mesmo para realizarse no campo social.

No caso das mulheres que participaram deste estudo, além de uma identidade social, apontaram encontrar no trabalho uma forma de "liberdade", que as desloca do aprisionamento e não reconhecimento das atividades domésticas. Para tanto, o trabalhar se configura como uma fonte de produção que gera transformação para os outros, neste caso, as crianças, mas também para elas

Conforme se pode observar:

Liberdade porque vindo para cá eu saio da minha rotina, pensando também na maternidade. Então aqui me vejo mais livre. Este é meu sentido porque o que fica difícil depois de ser mãe é fazer algo para si mesma, não tenho tempo para muita coisa. Então vir para cá é como se de alguma forma tivesse fazendo algo para mim, por isso que me sinto livre. Então o sentido do trabalho para mim é a liberdade que ele me dá. (MERENDEIRA-2).

A este modo, algumas trabalhadoras demonstraram ter encontrado em suas atividades um lugar de engenhosidade, ou seja, um modo de "fazer seu melhor", talvez porque neste contexto sentiremse autorizadas a colocar o a mais de si e assim sentir-se reconhecidas tanto pelo coletivo (pares e familiares) quanto por elas mesmas. Considere-se ainda que não apontam o fazer "melhor" apenas para o público atendido, mas também para sua família/ filhos. Compreendendo que continuar a trabalhar para estas mulheres não foi necessariamente um ato de escolha, já que umas encontram sentido em contribuir, outras o fazem porque "precisam", devido a uma "necessidade econômica". Todas, de alguma forma, criaram formas de dotar a atividade profissional fora de casa conforme se identifica nos trechos das entrevistas de duas participantes.
"Para mim o sentido é produzir, transformar a vida das crianças e a minha com minha família também!" (BERÇARISTA-2).

"O sentido de fazer meu melhor, porque foi tudo tão dificil para mim principalmente nesta fase pósparto, então quando saio de casa, já venho com a perspectiva de fazer meu melhor! Então para mim o sentido é produzir, transformar a vida das crianças e a minha com minha família também!" (AUXILIAR DE DESENVOLVIMENTO INFANTIL-2).

Sintetizando, Dejours (2012b, p. 114) afirma que a atividade profissional proporciona uma satisfação particular quando é livremente escolhida, permitindo assim tornar úteis pela sublimação, vocações existentes, impulsos pulsionais subsistentes ou constitucionalmente reforçados. No entanto, o trabalho, como via que leva a satisfação, é pouco apreciado por homens e mulheres. A grande maioria das pessoas trabalha apenas forçada pela necessidade de sobrevivência. Dessa aversão ao trabalho, que é exercido em meio a determinações sociais e históricas e, portanto, fonte de exploração e dominação, decorrem problemas sociais mais importantes.

No caso da presente pesquisa, o que se compreende é que a mulher não recebe o reconhecimento de trabalho efetivo no que tange as atividades reprodutivas, que continua compreendido como "coisas de casa". A este modo, ressignificar o sentido de ser trabalhadora e de trabalhar torna-se uma atividade ainda mais engenhosa, já que deverá dar um novo colorido tanto ao trabalho produtivo, quanto ao reprodutivo. Desta forma, refletir sobre o sentido que atribuem ao trabalhar, bem como as atividades que realizam, tornou-se uma possibilidade de emancipação social, pois nomeando o sentido que o trabalho tem para cada uma das trabalhadoras/ mães, tornam-se mais práticas as orientações em como auxiliá-las em seus papéis. Uma vez que o trabalho é rico de sentido individual e social, é um meio de produção da vida de cada um ao prover subsistência, criar sentidos existenciais ou contribuir 
na estruturação da identidade e da subjetividade de cada sujeito trabalhador.

\section{Considerações Finais}

Diante dos dados obtidos, compreende-se que além de ensinar e aprender, em seus discursos as mulheres trabalhadoras/mães trazem a afetividade como fator fundamental para o sentido do trabalho junto às crianças, mas também reconhecem que a busca pelo aprimoramento técnico é de extrema relevância para o desenvolvimento das atividades junto ao público infantil. Haja vista que este é um recorte da comunidade em desenvolvimento e, para tanto, necessitam não só compreensão de caráter pessoal, mas também estímulo profissional. Neste caso, o trabalho que realizam as provoca a estudar mais e se qualificar para o desenvolvimento das atividades.

Algumas participantes apontaram reconhecer no trabalho um lugar de liberdade, visto que este lhes atribui uma possibilidade de não se aterem apenas as questões domésticas, podendo assim ampliar o repertório existencial de modo mais engenhoso, o que as fazem sentir mais reconhecidas, seja por contribuírem socialmente, seja por sentirem-se além de uma dona de casa/mãe.

Cabendo aqui lembrar que no caso deste estudo, que tem como participantes unicamente mulheres, torna-se relevante salientar que tal sentido possui um lugar ainda mais desafiador, considerando que para elas é dado um papel de múltiplas funções, o que abarca tanto trabalho doméstico, ou seja, cuidar da casa em geral, trabalho reprodutivo e trabalho produtivo, aquele que por sua vez é reconhecido socialmente. O primeiro, embora traga um significado amplo inclusive no que tange ao desenvolvimento das atividades profissionais da família como um todo, ainda hoje mantém-se invisibilizado.

Por fim, considera-se que diante de tais achados, a contribuição desta pesquisa abarca tanto as reflexões acerca das mulheres trabalhadoras egressas de licença maternidade, quanto aqueles que em seu entorno se encontram. Haja vista que em detrimento das múltiplas funções que exercem socialmente, as mulheres buscam caminhos que possam levá-las a vivenciar seus papéis/identidade de modo real capaz de gerar satisfação e prazer, favorecendo também sua saúde mental. No sentido que se deve levar a sério a possibilidade de inscrever a relação com o trabalho como mediadora na construção da saúde como um todo, e em decorrência como meio extremamente importante de conjurar a angústia, o ressentimento e a violência que são contrapartidas ordinárias do sofrimento.

No entanto, a realização de novas pesquisas para aprofundar os resultados nesta já obtidos se faz relevante, pois quanto mais profundas forem as informações à comunidade em questão, mais caminhos de esclarecimentos se desenharão visando a junção trabalho versos maternidade.

\section{Referências}

DEJOURS, C. A banalização da injustiça social. Rio de Janeiro: Fundação Getúlio Vargas, 1999. . A loucura do trabalho. São Paulo: Oboré, 1987. . O fator humano. Rio de Janeiro: Fundação



1994.. Psicodinâmica do trabalho. São Paulo: Atlas,

. Trabalho vivo: sexualidade e trabalho. Brasília:

Paralelo 15, 2012a. t. 1.

. Trabalho vivo: trabalho e emancipação. Brasília: Paralelo 15,2012 b. t. 2.

. Uma nova visão do sofrimento humano nas organizações. In: CHALAT, J. (Coord.). O indivíduo na organização: dimensões esquecidas. 3. ed. São Paulo: Atlas, 2007. v. 1, p. 150-173.

DEJOURS, C.; ABDOUCHELI, E.; JAYET, C. Psicodinâmica do trabalho: contribuições da Escola Dejouriana à análise da relação prazer, sofrimento e trabalho. São Paulo: Atlas, 1994.

HEILMAN, M. E.; OKIMOTO, T. G. Motherhood: a pontential source of bias in employment decisions. The Journal of Applied Psychology, Washington, v. 93, n. 1, p. 189-198, 2008. 
HELOANI, R.; LANCMAN, S. Psicodinâmica do trabalho: o método clínico de intervenção e investigação. Production, v. 14, n. 3, p. 77-86, 2004.

LIMA, S. C. C. et al. O trabalho do cuidado: uma análise psicodinâmica. Revista Psicologia: Organizações \& Trabalho, Brasília, v. 12, n. 2, p. 203-215, 2012.

LOPES, R. C. S. No início eu saía com o coração partido...: as primeiras situações de separação mãe-bebê. Revista Brasileira de Crescimento e Desenvolvimento Humano, São Paulo, v. 15, n. 3, p. 26-35, 2005.

MARTINS, C. A.; ABREU, W. J. C. P.; FIGUEIREDO, M. C. A. B. Torna-se pai e mãe: um papel socialmente construído. Referência: Revista de Enfermagem, Coimbra, v. 4, n. 2, p. 121-131, 2014.

MOLINIER, P. A dimensão do cuidar no trabalho hospitalar: abordagem psicodinâmica do trabalho de enfermagem e dos serviços de manutenção. Revista Brasileira de Saúde Ocupacional, São Paulo, v. 33, n. 118, p. 6-16, 2008.

OLIVEIRA, I. G.; POLETTO, M. Vivências emocionais de mães e pais de filhos com deficiência. Revista da SPAGESP, Ribeirão Preto, v. 16, n. 2, p. 102-119,2015. Disponível em: <http://pepsic. bvsalud.org/scielo.php?script $=$ sci_arttextpid $=$ S1677$29702015000200009 \operatorname{lng}=\mathrm{ptnrm}=\mathrm{iso}>$. Acesso em: 27 out. 2016.

OLIVEIRA, N. T. Somatização e sofrimento no trabalho. Textos \& Contextos, Porto Alegre, v. 9, n. 2, p. 1-14, 2003.

PAVONI, M. P. et al. Privação de afeto e suas consequências: análise psicodinâmica a partir do filme "Precisamos Falar Sobre Kevin". Revista de Psicologia da IMED, Passo Fundo, RS, v. 7, p. 80-88, 2015.

PAZELLO, E. T. A maternidade afeta o engajamento da mulher no mercado de trabalho? Um estudo utilizando o nascimento de gêmeos como um experimento natural. Estudos Econômicos, São Paulo, v. 36, n. 3, p. 507-538, 2006.

PEREIRA, V. A. et al. Desenvolvimento do bebê nos dois primeiros meses de vida: variáveis maternas e sociodemográficas. Pensando Famílias, Porto Alegre, v. 18, n. 1, p. 64-77, jun. 2014. Disponível em: $<$ http://pepsic. bvsalud.org/scielo.php?script $=$ sci_arttextpid $=$ S 1679 $494 X 2014000100007 \operatorname{lng}=$ ptnrm=iso $>$. Acesso em: 23 out.2016.

PICCININI, C. A. et al. Gestação e a constituição da maternidade. Psicologia em Estudo, Maringá, v. 13, n. 1, p. 63-72, 2008.
PINQUART, M.; TEUBERT, D. Effects of parenting education with expectant and new parents: a metaanalysis. Journal of Family Psychology, Washington, v. 24, n. 3, p. 316-327, 2010.

PINTANEL, A. C.; GOMES, G. C.; XAVIER, D. M. Mães de crianças com deficiência visual: dificuldades e facilidades enfrentadas no cuidado. Revista Gaúcha de Enfermagem, Porto Alegre, RS, v. 34, n. 2, p. 86-92, 2013.

RIBEIRO, C. V. S.; LEDA, D. B. O significado do trabalho em tempos de reestruturação produtiva. Estudos e Pesquisas em Psicologia, Rio de Janeiro, v. 4, n. 2, p. 76-83, 2004.

ROCHA, M.; MOTA, C. P.; MATOS, P. M. Vinculação à mãe e ligação aos pares na adolescência: o papel mediador da auto-estima. Análise Psicológica, Lisboa, v. 29, n. 2, p. 185-200, abr. 2011. Disponível em: <http://www. scielo.mec.pt/scielo.php?script $=$ sci_arttextpid $=$ S0870$823120110002000011 \mathrm{lng}=\mathrm{ptnrm}=$ iso $>$. Acesso em: 23 out. 2016.

RODRIGUES, O. M. P. R.; BOLSONI-SILVA, A. T. Efeitos da prematuridade sobre o desenvolvimento de lactentes. Revista Brasileira de Crescimento e Desenvolvimento Humano, São Paulo, v. 21, n. 1, p. 111$121,2011$.

RONCALlO, P. C. A; MIGUEL, S. M.; FREIJO, H. A. Vínculo materno-fetal: implicaciones en el desarrollo psicológico y propuesta de intervension en atencion temprana. Escritos de Psicologia, Málaga, v. 8, n. 2, p. 14-23, maio/ago. 2015.

SILVA, S. G. Do feto ao bebê: Winnicott e as primeiras relações materno-infantis. Psicologia Clínica, Rio de Janeiro, v. 28, n. 2, p. 29-54, 2016. Disponível em: $<$ http://pepsic.bvsalud.org/scielo.php? script $=$ sci arttextpid=S0103-566520160002000031ng $=$ ptnrm $=\mathrm{iso}>$. Acesso em: 23 out. 2016.

SOUZA, L. R.; RIOS-NETO, E. L.; QUEIROZ, B. L. A relação entre parturição e trabalho feminino no Brasil. Revista Brasileira de Estudos de População, Campinas, SP, v. 28, n. 1, p. 57-79, 2011.

TURATO, E. R. Tratamento da metodologia da pesquisa clínico-qualitativa: construção teórico-epistemológica, discussão comparada e aplicação nas áreas da saúde humanas. Rio de Janeiro: Vozes, 2003.

Recebido em: 08 jul. 2018 Aceito em: 21 ago. 2018 